\title{
The Relationship of Body Image with Emotion Regulation, Stress, and Aggression and their Comparison Between Males and Females With Multiple Sclerosis
}

\author{
Ali Farnam, ${ }^{1}$ Faride Marashi, ${ }^{2}$ and Melika Sana'tnama ${ }^{2}$ \\ ${ }^{1}$ Department of Psychology, Faculty of Education and Psychology, University of Sistan and Baluchestan, Zahedan, IR Iran \\ ${ }^{2}$ MA of Psychology, Faculty of Education and Psychology, University of Sistan and Baluchestan, Zahedan, IR Iran \\ "Corresponding author: Ali Farnam, Department of Psychology, Faculty of Education and Psychology, University of Sistan and Baluchetsan, Zahedan, IR Iran. Tel: \\ +98-9214326588, E-mail: farnam@ped.usb.ac.ir
}

Received 2017 April 09; Revised 2017 May 22; Accepted 2017 June 26.

\begin{abstract}
Background and Objectives: Multiple sclerosis is one of the most prevalent chronic diseases of the central nervous system, which has a disabling nature. This study aimed at investigating the relationship of body image with emotion regulation, stress, and aggression and to compare them between males and females with multiple sclerosis (MS).

Methods: The current study was correlational with a casual-comparative design. The statistical population of this study included all MS patients referred to the MS society of Zahedan from November 2016 to January 2017. Among these individuals, 60 patients (30 males and 30 females) were selected using a convenience sampling method and were asked to fill out four questionnaires including the Cash, Winstead, and Janda body image questionnaire, Abell index of stress, self-regulation inventory (SRI-25), and buss and perry aggression questionnaire.

Results: The obtained data was analyzed using the Pearson correlation coefficient, stepwise regression analysis, multiple analysis of variance (MANOVA), and t-test. Results of the correlation test indicated that body image was significantly and negatively correlated with stress $(r=-0.259, \mathrm{P}<0.05)$ and aggression $(r=-0.258, \mathrm{P}<0.05)$. However, no significant correlation was found between body image and emotion regulation $(r=0.156, P>0.05)$. Results of the regression analysis demonstrated that body image was a predictor of stress and among its 6 subscales, appearance evaluation, body area satisfaction, and fitness orientation were able to determine 0.27 of variances in stress. Moreover, aggression was a predictor of body image, such that among its six subscales, fitness evaluation and body area satisfaction explained a total of 0.23 of variances in aggression. Results of the MANOVA and t-test revealed that considering body image, stress, emotion regulation, and aggression, there were significant differences between males and females with MS $(\mathrm{P}<0.05)$.

Conclusions: Given the obtained results, through training skills aimed at improving body image among MS patients, these patients could be aided to decrease their stress in the face of stressful events and, consequently, control their aggressive behaviors.
\end{abstract}

Keywords: Body Image, Emotion Regulation, Stress, Aggression, Multiple Sclerosis (MS)

\section{Background}

Multiple sclerosis is a kind of progressive and degenerative disease in which the myelin sheath of nerve cells is damaged (1). Nowadays, the number of people with MS is growing. Nearly 50,000 people suffer from this disease in Iran (2). In Sistan and Baluchestan province, the lowest MS prevalence rate is 6 per 100,000 population. Most MS patients are in the age range of 20 to 30 years old (3) and the MS prevalence rate is higher among females compared to males (4). Given its increasing prevalence and mortality rate, high costs it imposes on MS patients, and numerous issues it creates for them, paying attention to and taking care of these patients and attempting to decrease their issues and improve symptoms of the disease seem essential. Studies have shown that patients with MS, compared to healthy individuals, experience higher levels of mental disorders, such as stress and anxiety (5). Hence, stress is among factors affecting MS. Without a doubt, stress and mental factors play key roles in the development of this disease and the onset of its new attacks (6). Stress is among issues, which has recently been considered in various fields of psychology and is one of the major reasons for many maladjustments and mental disorders (7). Therefore, stressful events are significantly related to MS (1) and stress plays a predictive role in body image such that people with high levels of stress report high negative body image perceptions (8). This is while gender is a key determinant in studies carried out on body image and stress among adolescents. Females are twice as likely as males to be dissatisfied with their bodies and to experience stress

Copyright ( $)$ 2017, Jundishapur Journal of Chronic Disease Care. This is an open-access article distributed under the terms of the Creative Commons 
(9). In this regard, Madison (2012), Murray, Byrne, and Rieger (2011), and Paxton (2002) examined the relationship between stress and body image.

Another important factor affecting MS is emotion regulation. The association between body image and emotion regulation is a significant factor, which plays an important role in mental health and has received little attention (10). Emotion regulation is a key factor in determining well-being and successful performance and plays an important role in coping with stressful events (11). Emotion regulation is a process in which emotions are adjusted automatically or voluntarily to facilitate a desired state or a target, through applying internal processes together with external interpersonal impacts (12). Romer and Gratz believe that emotional regulation includes being aware of and perceiving emotions, accepting emotions, having the ability to control impulsive behaviors and behave in accordance with the considered goals when experiencing negative emotions, and having the ability to apply appropriate emotion regulation strategies to modulate emotional responses in order to achieve individual goals and situational demands. Additionally, they argue that difficulties in emotion regulation are associated with low levels of well-being (13). People with MS often deal with attention lapses and failures in applying effective emotion regulation strategies (14). A failure in emotion regulation is a predictor of low quality of life (15). Hughes and Gullone (2011) and Phillips et al. investigated the relationship between body image and emotion regulation. Anger is among emotions, which plays an effective and important role in people's lives (16). Anger is one of the most fervent excitements that could be created in various ways and could have numerous impacts on different aspects of people's physical and mental health (17). On the other hand, aggression is a personality trait that makes people vulnerable to explore high-risk experiences, including having a tendency to abuse drugs. Researchers attributed the onset of aggressive behaviors to various causes (18). Several studies have indicated that the image one has of himself/herself is one of the most important causes of issues that clearly change his/her viewpoint. As an instance, when someone thinks that, due to an illness, he/she is worth less than others, he/she develops a negative self-image. This feeling of inferiority is related to several emotions like anger, depression, and stress and it affects the person's quality of life (19). Accordingly, Kartal et al. (2016) and Jenssena and Johannessenb (2015) studied the relationship between body image and aggression. Body image is a psychological structure and is considered as a central concept by health psychologists (20). The term body image has 2 dimensions, i.e. perceptual and attitudinal. While the perceptual dimension of body image refers to how a person perceives his/her size, shape, weight, face, movements, and actions, the attitudinal dimension is associated with how he/she feels about these features and how these feelings control his/her behaviors (21). Due to the significant role body image plays in social interactions and interpersonal relations, it has received great attention from mental health professionals (22). It seems that people, who feel good about themselves, usually have good feelings about their lives (23). Indeed, a positive body image creates a sense of self-worth and a mental image, which has changed in any way, leads to changes in one's self-worth (24). In this regard, Safir, Flaisher-Kellner, and Rosenmann (2005) compared body image between males and females. Hence, the present study sought to answer the following research questions:

- Is body image related to emotion regulation, stress, and aggression among people with Multiple Sclerosis (MS)?

- Are there any statistically significant differences between body image, emotion regulation, stress, and aggression between males and females with MS?

\section{Methods}

\subsection{Research Method, Statistical Population, and Sample}

The current study was correlational with a casualcomparative design. The statistical population of this study included all patients with MS referred to the MS Society of Zahedan from November 2016 to January 2017. Among these people, based on the Morgan's sample size table, 60 patients (30 males and 30 females) were selected using the convenience sampling method. Among criteria for inclusion of the patients referred to the MS Society of Zahedan in this study, being able to read and write and having adequate physical and mental health to write could be mentioned. Exclusion criteria of the current study included having a history of other diseases such as mental disorders, cognitive disorders, recurrence of the disease, and hospitalization.

\subsection{Data Collection Method}

Within 2 months from November 2016 to January 2017, the questionnaires were randomly distributed among 60 patients with MS, who were eager to take part in this study. The subjects were asked to aid the authors to conduct this study through filling out the questionnaires and answer these questionnaires anonymously, precisely, and honestly. They only mentioned their gender in the questionnaires. Moreover, the subjects were ensured that the obtained data would remain strictly confidential. 


\subsection{Ethical Considerations}

After explaining the objectives of this study and the method of filling out the questionnaires, informed consent forms were signed by eligible patients. Afterwards, the questionnaires were distributed among the patients. Whenever a question seemed vague, some additional explanations were provided. It should be noted that these explanations were provided to avoid ambiguity and/or bias. Information related to each subject was not detectable and a code was only assigned to each patient.

\subsection{Measurement Tools}

\subsubsection{The Body Image Questionnaire}

This questionnaire was developed to assess body image. This 46-item self-report questionnaire was designed by Cash, Winstead, and Janda in 1981 and 1986 based on a 5point scale. In the present study, a version revised by Cash (1997) was applied. Subscales of this questionnaire are as follows: 1. Appearance evaluation, 2. Appearance orientation, 3. Fitness evaluation, 4. Fitness orientation, 5. Concern with weight gain, and 6 . Body area satisfaction. This questionnaire is scored based on a 5-point Likert-type scale (ranging from $1=$ totally disagree to $5=$ totally agree). The scores are in the range of 46 to 230 . This questionnaire contains 2 scales, including subscales of appearance evaluation, with a reliability of 0.81 , measured using the testretest reliability and a Cronbach's alpha coefficient of 0.88 , and body area satisfaction, with a reliability of 0.86 and a Cronbach's alpha coefficient of 0.77 (25). In a study conducted by Raghibi and Minakhani, the Cronbach's alpha coefficients of the entire questionnaire and its subscales were respectively $0.74,0.71,0.78,0.66,0.76,0.80$, and 0.74 (26). In this study, the reliability of this questionnaire was 0.72 .

\subsubsection{The Index of Clinical Stress (ICS)}

This index was designed by Abell in 1991 to measure subjective mental pressure. This 25 -item index evaluates the degree or severity of issues associated with mental pressure. This index aids an examiner to assess perceived stress without considering stress-related issues caused by everyday life events. This is a self-report index and a subject should determine the extent to which each item is true about him/her on a 7-point Likert-type scale (ranging from $1=$ never to $7=$ always). The internal consistency of the index of Clinical Stress was desirable. Its Cronbach's alpha was 0.96. The significant correlations of the score of the index of clinical stress with the public commitment scale and the family relations index indicated its desirable construct validity. In addition, the obtained results confirmed the factor validity of the index of clinical stress (27). In the present study, reliability of this index was 0.61 .

\subsubsection{The Self-Regulation Inventory (SRI-25)}

This 25-item inventory evaluates self-regulation by five specific factors, including positive actions, controllability, expression of feelings and needs, assertiveness, and wellbeing seeking. This inventory is scored based on a 5-point Likert-type scale (ranging from $1=$ very low to $5=$ very high). The Cronbach's alpha coefficients of this inventory ranged from 0.68 to 0.84 , which confirmed this inventory's internal consistency (28). Examining the psychometric properties of its Persian version on a sample of 676 university students showed that the Cronbach's alpha coefficients of its subscales ranged from 0.90 to 0.97 . This confirmed its desirable internal consistency (29). In the current study, reliability of this inventory was 0.82 .

\subsubsection{The Aggression Questionnaire}

This self-report questionnaire was developed by Buss and Perry (1992). This questionnaire includes 29 items and measures 4 subscales, i.e. physical aggression (9 items), verbal aggression (5 items), anger (7 items), and hostility (8 items). This questionnaire is scored based on a 5-point Likert-type scale (ranging from $5=$ totally agree to $1=$ totally disagree) (30). Using the Cronbach's alpha coefficient, test-retest reliability procedure, and split-half method, Mohammadi indicated that reliability of this scale was respectively $0.89,0.78$, and 0.73 . Moreover, through calculating correlation coefficients of its subscales with each other, he demonstrated that convergent validity of this questionnaire was significant and ranged from 0.37 to 0.78 (31). In this study, reliability of this questionnaire was 0.74 .

Data analyses were conducted at both descriptive and inferential levels. In the descriptive level, the frequency, percentage, mean, and standard deviation were used and in the inferential level, the Pearson correlation coefficient, stepwise regression analysis, and multiple analysis of variance (MANOVA) were conducted using the SPSS16 software.

\section{Results}

The descriptive results (means and standard deviations) related to the variables and their subscales are presented in Table 1.

Is body image significantly related to stress, emotion regulation, and aggression?

To answer the abovementioned question, the Pearson correlation coefficient was used, the results of which are presented in Table 1 . This correlation test is applied whenever at least 2 variables are regarded and the variables are interval or relative. As indicated, body image was significantly and negatively correlated with stress $(\mathrm{r}=-0.259, \mathrm{P}<$ 0.05). However, since the level of significance was greater 


\begin{tabular}{|c|c|c|c|c|}
\hline Variable & Subscales & Males & Females & Total \\
\hline \multirow{7}{*}{ Body image } & Appearance evaluation & $20.77 \pm 2.08$ & $21.03 \pm 2.29$ & $20.88 \pm 2.17$ \\
\hline & Appearance orientation & $42.86 \pm 2.71$ & $43.76 \pm 3.01$ & $43.31 \pm 2.87$ \\
\hline & Fitness evaluation & $11.66 \pm 1.62$ & $12.13 \pm 1.16$ & $11.90 \pm 1.42$ \\
\hline & Fitness orientation & $42.26 \pm 4.12$ & $43.36 \pm 2.78$ & $42.81 \pm 3.53$ \\
\hline & Concern with weight gain & $3.70 \pm 0.98$ & $4.60 \pm 1.45$ & $4.15 \pm 1.31$ \\
\hline & Body area satisfaction & $26.86 \pm 2.40$ & $27.93 \pm 3.65$ & $27.40 \pm 3.11$ \\
\hline & Total body image & $1.46 \pm 6.15$ & $1.49 \pm 8.73$ & $1.48 \pm 7.65$ \\
\hline Stress & Total stress & $1.19 \pm 4.39$ & $1.20 \pm 8.86$ & $1.20 \pm 6.96$ \\
\hline \multirow{6}{*}{ Emotion regulation } & Positive actions & $19.40 \pm 1.79$ & $19.40 \pm 1.88$ & $19.40 \pm 1.82$ \\
\hline & Controllability & $18.76 \pm 2.20$ & $18.13 \pm 1.97$ & $18.45 \pm 2.10$ \\
\hline & Expression of feelings and needs & $18.56 \pm 1.99$ & $17.40 \pm 2.17$ & $17.98 \pm 2.15$ \\
\hline & Assertiveness & $18.31 \pm 2.36$ & $17.67 \pm 1.78$ & $17.99 \pm 2.100$ \\
\hline & Well-being seeking & $20.67 \pm 2.69$ & $19.93 \pm 2.19$ & $20.30 \pm 2.46$ \\
\hline & Total emotion regulation & $95.48 \pm 7.69$ & $93.42 \pm 4.89$ & $94.45 \pm 6.47$ \\
\hline \multirow{5}{*}{ Aggression } & Physical aggression & $26.36 \pm 2.45$ & $25.93 \pm 2.51$ & $26.15 \pm 2.47$ \\
\hline & Verbal aggression & $14.73 \pm 1.55$ & $14.90 \pm 1.34$ & $14.81 \pm 1.44$ \\
\hline & Anger & $22.23 \pm 2.66$ & $21.96 \pm 2.38$ & $22.10 \pm 2.50$ \\
\hline & Hostility & $27.66 \pm 1.74$ & $26.26 \pm 2.21$ & $26.96 \pm 2.09$ \\
\hline & Total aggression & $90.40 \pm 4.37$ & $89.60 \pm 5.47$ & $90.00 \pm 5.09$ \\
\hline
\end{tabular}

${ }^{\mathrm{a}}$ Values are expressed as mean $\pm \mathrm{SD}$

than 0.05 , there was no significant correlation between body image and emotion regulation $(r=0.156, \mathrm{P}>0.05)$. This is while there was a significant and negative correlation between body image and aggression $(\mathrm{r}=-0.258, \mathrm{P}<$ 0.05).

Are the subscales of body image a predictor of stress among males and females with MS?

To answer the abovementioned question, stepwise regression analysis was applied. This type of regression analysis is used whenever examining the impact of several independent variables (interval or relative) on a dependent variable is targeted. The results demonstrated that in the first step, appearance evaluation was entered in the regression equation and was able to determine 0.14 of the variance in stress. In the second step, appearance evaluation and body area satisfaction were respectively entered in the regression equation and they determined a total of 0.21 of the variance in stress. In the third step, appearance evaluation, body area satisfaction, and fitness orientation were respectively entered in the regression equation and they determined a total of 0.27 of the variance in stress. In other words, the standardized beta coefficients indicated that one unit variation in the score of stress changed the variance in appearance evaluation by -0.39 in the first model, changed the variances of appearance evaluation and body area satisfaction by 0.31 in the second model, and changed the variances in appearance evaluation, body area satisfaction, and fitness orientation by -0.26 in the third model.
For males with MS, in the first step, fitness orientation was able to predict 0.14 of the variance in the criterion variable (stress) and, according to the value of the adjusted Rsquared, it had the greatest predictive power. Due to a lack of relationship with stress, the other subscales of body image were omitted. For the females with MS, in the first step, appearance evaluation was able to predict 0.18 of the variance in the criterion variable (stress) and, according to the value of the adjusted R-squared, it had the greatest predictive power. In the second step, appearance evaluation and body area satisfaction were able to predict a total of 0.29 of the variance in stress. Due to a lack of having any relationship with stress, the other subscales of body image were eliminated. Therefore, the obtained results revealed that none of the subscales of body image predicted emotion regulation.

Are the subscales of body image predictors of aggression among males and females with MS?

To answer the abovementioned question, the stepwise regression analysis was used. The results demonstrated that in the first step, fitness evaluation was entered in the regression equation and was able to determine 0.17 of the variance in aggression. In the second step, fitness evaluation and body area satisfaction were respectively entered in the regression equation and they determined a total of 0.23 of the variance in aggression. In other words, the standardized beta coefficients indicated that one unit variation in the score of aggression changed the variance in fit- 
ness evaluation by - 0.43 in the first model and changed the variances in fitness evaluation and body area satisfaction by -0.26 in the second model. For the males with MS, in the first step, fitness evaluation was able to predict 0.18 of the variance in the criterion variable (aggression). In the second step, fitness evaluation and body area satisfaction were able to predict a total of 0.40 of the variance in aggression. Due to a lack of having relationships with aggression, the other subscales of body image were omitted. For the females with MS, in the first step, fitness evaluation was able to predict 0.17 of the variance in the criterion variable (aggression) and, according to the value of the adjusted Rsquared, it had the greatest predictive power. Due to the lack of having any relationships with aggression, the other subscales of body image were eliminated.

To answer the following research question, i.e. are there any statistically significant differences between body image, emotion regulation, and aggression between males and females with MS? the obtained data was analyzed by the multivariate analysis of variance (MANOVA). This type of analysis is used whenever examining the impact of one independent variable on more than one dependent variable is targeted. To trust the results obtained from this type of analysis, the following conditions should be met. One of the assumptions of the multivariate analysis of variance is homogeneity of variance-covariance matrices. To assess this assumption, the box's test of equality of covariance matrices was used (Box's $M=11.08, F=1.74, P=0.107>0.05$ ). The level of significance of the Box's test was greater than 0.05 ; therefore, it could be concluded that the variancecovariance matrix was homogeneous.

To investigate the homogeneity of variances of the 2 groups, the Levene's Test for equality of variances was applied. The results of the Levene's test were not statistically significant for any of the variables under study (body image: $\mathrm{F}(1,58)=-0.040, \mathrm{P}=0.84>0.05$, emotion regulation: $\mathrm{F}(1,58)=-0.002, \mathrm{P}=0.96>0.05$, assurance: $\mathrm{F}(1,58)=5.93$, $\mathrm{P}=0.55>0.05$, need to control thoughts: $\mathrm{F}(1,58)=2.74, \mathrm{P}$ $=0.1>0.05$, and cognitive self-awareness: $\mathrm{F}(1,58)=3.54, \mathrm{P}$ $=0.06>0.05)$. Therefore, the assumption of homogeneity of variances was confirmed. This indicates that the following results are reliable.

The results of the MANOVA revealed statistically significant differences in the means of body image, emotion regulation, and aggression between males and females ( $\mathrm{F}=$ 2.00, Wilks' Lambda $=0.903, \mathrm{P}=0.05)$. Therefore, given the value of eta-squared (56.00), there were statistically significant differences between these 2 groups considering 3 variables of body image, emotion regulation, and aggression. Moreover, the power of the test (0.97) indicated adequacy of the sample size and its large effect size.

The results presented in Table 2 showed the effects among the subjects (between the groups). Given the value of $\mathrm{F}$, the differences in body image, emotion regulation, and aggression between the males and females with MS were significant at the level of $\mathrm{P} \leq 0.05$.

Are there any statistically significant differences in stress between males and females with MS?

To answer the abovementioned question, the independent t-test was used. This test is used whenever 2 groups are needed to be compared with regards to an interval variable. With regards to stress, the results showed a statistically significant difference between the males and females with MS $(\mathrm{t}=-0.219, \mathrm{P}<0.05)$; therefore, given the mean scores of these 2 groups, it could be inferred that the females experienced higher levels of stress compared to the males. On other words, considering stress, there was a statistically significant difference between males and females with MS.

\section{Discussion}

The main objective of the current study was to examine the predictive role of body image in stress, emotion regulation, and aggression among males and females with Multiple Sclerosis (MS). The results obtained from this study are presented in Tables 3 and are consistent with part of the results obtained from several previous studies (9-11, 31-33). In a study conducted by Murray et al. the results indicated that the association between body image and emotion regulation was one of the significant factors, which played a key role in mental health and had received little attention. Moreover, body image cannot play a mediating role in emotion regulation (10). To explain these results, it could be mentioned that emotion regulation is one of the factors affecting MS, which has received little attention and is a significant factor in determining well-being and successful performance and in coping with stressful events (11). Body image has a predictive role in emotion regulation. This is not consistent with the results obtained from the current study. To explain this finding, it could be mentioned that people who have negative perceptions about themselves usually apply negative emotion regulation strategies and are not able to properly regulate their emotions (32). The results of Kartal Yagiz et al. (2016) showed that body image was significantly and negatively related to aggression. They found that the scores of body image were negatively correlated with anger among people with social anxiety (33). Khanjani and Bahadori Khosroshahi examined the relationship between aggression and body image concerns among anabolic androgenic steroid users and demonstrated that when these people were at risk, they displayed aggressive behaviors. Therefore, to explain these results, it could be suggested that body image concerns 
Table 2. The Results of the Multivariate Analysis of Variance (MANOVA) Related to Body Image, Emotion Regulation, and Aggression in two Groups of Males and Females With Multiple Sclerosis

\begin{tabular}{|c|c|c|c|c|c|c|c|}
\hline Variable & Dependent & Sum of Squares & Df & Mean of Squares & $\mathbf{F}$ & Sig & Eta-Squared \\
\hline \multirow{3}{*}{ Group } & Body image & 101.40 & 1 & 101.40 & 1.75 & 0.005 & 0.029 \\
\hline & Emotion regulation & 62.83 & 1 & 62.83 & 1.51 & 0.005 & 0.025 \\
\hline & Aggression & 64.06 & 1 & 64.06 & 2.53 & 0.005 & 0.045 \\
\hline \multirow{3}{*}{ Error } & Body image & 3352.93 & 58 & 57.80 & - & - & - \\
\hline & Emotion regulation & 2410.99 & 58 & 41.56 & - & - & - \\
\hline & Aggression & 1465.93 & 58 & 25.27 & - & - & - \\
\hline
\end{tabular}

are a risk factor for these people and it leads to aggression (34). According to the results obtained from this study, there was a negative significant relationship between body image and stress. This finding is in line with the results of Madison (2012), which indicated that body image was significantly and negatively related to physiological stress among females. To determine the results obtained from this study, it could be mentioned that females, who care more about their appearances experience high levels of negative body image and stress (8). Noble (2012) found that stress among adolescents played a key role in developing mental and psychological problems. Body image predicts a significant part of the variance in stress and females are twice as likely as males to be dissatisfied with their bodies and to experience stress (9). Paxton (2002) indicated that stress during adolescence could lead to inefficient development of body image (35). To explain the abovementioned results, it could be stated that a person's perception of his/her body is among factors affecting stress. A person's perception of his/her body includes a significant part of his/her self-concept. A person communicates with the world through his/her body and his/her body is the most visible part of a person's self-awareness. Body image is the internal representation of a person's external appearance. This representation includes physical, perceptual, and attitudinal dimensions. This is why a distorted perception of body image plays an important role in physical and psychological health (36).

Table 3. The Correlation Coefficients of Body Image With Stress, Emotion Regulation, and Aggression

\begin{tabular}{lccc}
\hline Variable & Stress & Emotion Regulation & Aggression \\
\hline Body image & $-0.259^{*}$ & 0.156 & $-0.258^{\mathrm{a}}$ \\
\hline${ }^{\mathrm{a}} \mathrm{P}<0.05$. & & & \\
\end{tabular}

The results of the current study revealed that there were statistically significant differences in body image, emotion regulation, stress, and aggression between males and females with MS (Tables 2 and 7). These findings are consistent with part of the results obtained from several previously carried out studies (11,32-36). Safir et al. showed that females, compared to males, were more likely to be dissatisfied with the size and shape of their bodies (37). Vakili et al. in a study aimed to examine the relationship between body image concerns and social anxiety, concluded that body image and physical attractiveness were more important for females and adolescents in comparison with other strata of the society (38). Purshhryary stated that females, compared to males, experienced higher levels of dissatisfaction with their bodies (39). To explain the obtained results, it could be noted that although both males and females pay a lot of attention to body image, body image is of significant importance to females. The current social standards of female beauty, stress on the tendency to be skinny in an extreme way. Many studies have demonstrated that females were significantly dissatisfied with the size and shape of their bodies. Therefore, females are easily prone to body image issues (37). Additionally, the results demonstrated a significant difference in aggression between males and females with MS. This finding is in line with the results of Shokri et al. which showed that male's scores on aggressive behaviors and dimensions of aggression and physical anger and female's scores on verbal aggression were high (40). To determine these results, it could be mentioned that males and females experience anger in totally different ways. Males tend to show their anger, while females tend to hide their anger. In fact, anger could be considered as a masculine characteristic and it is usually displayed in a physical way; however, females often consider anger as an unacceptable and unfeminine tool. Hence, they show their anger in a verbal way (41). Furthermore, the results indicated a significant difference in stress between the males and females with MS. Indeed, Rayegan et al. in one study, revealed that body image was significantly and negatively related to stressors and females were twice as likely as males to experience stress 
Table 4. The Results of the Regression Analysis Conducted to Predict Stress via the Subscales of Body Image ${ }^{\mathrm{a}}$

\begin{tabular}{|c|c|c|c|c|c|c|}
\hline Group & Step & Correlation Coefficient & $\begin{array}{c}\text { Square of the Correlation } \\
\text { Coefficient }\end{array}$ & Adjusted $\mathbf{R}^{2}$ & $\beta$ & Sig \\
\hline \multirow{3}{*}{ Total } & Appearance evaluation & 0.394 & 0.155 & 0.141 & -0.394 & 0.005 \\
\hline & $\begin{array}{l}\text { Appearance evaluation and } \\
\text { body area satisfaction }\end{array}$ & 0.496 & 0.246 & 0.219 & 0.316 & 0.005 \\
\hline & $\begin{array}{l}\text { Appearance evaluation, body } \\
\text { area satisfaction, and fitness } \\
\text { orientation }\end{array}$ & 0.559 & 0.312 & 0.275 & -0.263 & 0.005 \\
\hline Males & Fitness orientation & 0.419 & 0.176 & 0.146 & -0.419 & 0.005 \\
\hline \multirow{2}{*}{ Females } & Appearance evaluation & 0.465 & 0.216 & 0.188 & 0.465 & 0.005 \\
\hline & $\begin{array}{l}\text { Appearance evaluation and } \\
\text { body area satisfaction }\end{array}$ & 0.588 & 0.362 & 0.296 & 0.360 & 0.005 \\
\hline
\end{tabular}

${ }^{\mathrm{a}}$ Criterion variable: stress.

Table 5. The Results of the Regression Analysis Conducted to Predict Aggression Via the Subscales of Body Image ${ }^{\mathrm{a}}$

\begin{tabular}{|c|c|c|c|c|c|c|}
\hline Group & Step & Correlation Coefficient & $\begin{array}{c}\text { Square of the Correlation } \\
\text { Coefficient }\end{array}$ & Adjusted $\mathbf{R}^{2}$ & $\mathrm{~B}$ & Sig \\
\hline \multirow{2}{*}{ Total } & Fitness evaluation & 0.435 & 0.189 & 0.175 & -0.435 & 0.005 \\
\hline & $\begin{array}{l}\text { Fitness evaluation and body } \\
\text { area satisfaction }\end{array}$ & 0.506 & 0.256 & 0.230 & -0.261 & 0.005 \\
\hline \multirow{2}{*}{ Males } & Fitness evaluation & 0.461 & 0.213 & 0.184 & -0.461 & 0.005 \\
\hline & $\begin{array}{l}\text { Fitness evaluation and body } \\
\text { area satisfaction }\end{array}$ & 0.670 & 0.448 & 0.408 & -0.493 & 0.005 \\
\hline Females & Fitness evaluation & 0.453 & 0.205 & 0.177 & -0.453 & 0.005 \\
\hline
\end{tabular}

${ }^{\text {a }}$ Criterion variable: aggression.

Table 6. Demographic Information of the Subjects

\begin{tabular}{l|c|c|c}
\hline \multirow{4}{*}{ Education } & Variable & Percent & Percent \\
\hline & Illiterate & 12 & 19.7 \\
\cline { 2 - 4 } & Elementary school & 10 & 16.4 \\
\cline { 2 - 4 } & Middle school & 23 & 37.7 \\
\cline { 2 - 4 } & Diploma and higher & 15 & 24.6 \\
\hline \multirow{3}{*}{ Marital status } & Single & 24 & 40 \\
\hline \multirow{3}{*}{ Gender } & Married & 36 & 60 \\
\cline { 2 - 4 } & Male & 30 & 50 \\
\hline \multirow{3}{*}{ Age } & Female & 30 & 50 \\
\cline { 2 - 4 } & $18-28$ & 30 & 50 \\
\cline { 2 - 4 } Total & $29-39$ & 17 & 28.3 \\
\hline
\end{tabular}

(35). To explain these results, it could be mentioned that females, compared to males, evaluate threatening events with higher levels of stress. Therefore, they are more prone to stress (40). With regards to emotion regulation, the results revealed a significant difference between males and females with MS. This finding is consistent with the results of Martin and Dahlen (2005), which demonstrated a statistically significant difference between males and females with regards to emotion regulation (41). Furthermore, this finding is in line with the results of Hughes and Gullone (2011), which indicated a difference between males and females in the level of emotion regulation and demonstrated that males, compared to females, obtained higher scores on positive self-acceptance (41). Emotion regulation strategies are employed to deal with stress and negative life events. When encountering negative events, females, compared to males, use more negative strategies, including catastrophizing, rumination, and the like. In general, in comparison with males, females tend to blame themselves when dealing with negative events and focus on their sadness and distress. Therefore, while females apply non-adaptive strategies to cope with their issues, males consider positive aspects of issues and employ more adaptive strategies to deal with them. 
Table 7. The Results of the Independent t-Test Conducted to Examine Stress in two Groups of Males and Females With Multiple Sclerosis

\begin{tabular}{|c|c|c|c|c|c|c|c|}
\hline \multirow[t]{2}{*}{ Variable } & \multicolumn{2}{|c|}{ Levene's test } & \multirow{2}{*}{$\begin{array}{c}\text { Men } \\
\mathbf{M} \pm \mathbf{S D}\end{array}$} & \multirow{2}{*}{$\begin{array}{l}\text { Women } \\
\mathbf{M} \pm \mathrm{SD}\end{array}$} & \multirow[t]{2}{*}{$\mathbf{T}$} & \multirow[t]{2}{*}{ df } & \multirow[t]{2}{*}{ Sig } \\
\hline & $\mathbf{F}$ & Sig & & & & & \\
\hline Stress & 0.458 & 0.558 & $1.18 \pm 6.18$ & $1.22 \pm 7.22$ & -2.19 & 58 & 0.05 \\
\hline
\end{tabular}

\subsection{Conclusions}

Given the results obtained from the current study, it could be concluded that body image played a predictive role in aggression, stress, and anxiety among the patients with MS; however, it did not play a predictive role in emotion regulation. Since stressors are very problematic for patients with MS, attempting to control these factors and handle aggression and anxiety may aid these patients to improve their body image. Unlike previously conducted studies, the current study examined the relationships among body image, emotion regulation, stress, and aggression, investigated their predictive roles, and compared these variables between males and females with MS. This study faced a number of limitations, including the small sample size, limited number of subjects, and problems in getting access to the considered sample; therefore, cautious should be exercised when generalizing the obtained results. Certainly, further studies should be conducted to generalize these results. Implications for future studies are as follows: in the present study, only body image, emotion regulation, stress, and aggression were considered, while it seemed that a number of other variables were also effective. Accordingly, similar studies are also needed to be conducted on other populations. Some implications for practice are as follows: workshops aimed at training emotion regulation and anger and stress management skills could be held for patients with MS and their families and some brochures on regulating and controlling emotions, anger, and stress could be provided for hospital staff, MS patients, their families, and the Society of MS to aid these patients to promote their awareness.

\section{References}

1. Esmaeili M, Hosseini F. Multiple sclerosis and stressful thought habit. Iran J Nurs Res. 2009;3(11):25-32.

2. Khayeri F, Rabiei L, Shamsalinia A, Masoudi R. Effect of Fordyce Happiness Model on depression, stress, anxiety, and fatigue in patients with multiple sclerosis. Complement Ther Clin Pract. 2016;25:130-5. doi: 10.1016/j.ctcp.2016.09.009. [PubMed: 27863602].

3. Ghorbani E, Issazadegan A, Saffarinia M. The Relationship between Cognitive Emotion Regulation Strategies and Perceived Social Support among Individuals with Multiple Sclerosis. Int Res J Appl Basic Sci. 2012;3.

4. Prokopova B, Hlavacova N, Vlcek M, Penesova A, Grunnerova L, Garafova A, et al. Early cognitive impairment along with decreased stress-induced BDNF in male and female patients with newly diagnosed multiple sclerosis. J Neuroimmunol. 2017;302:34-40. doi: 10.1016/j.jneuroim.2016.11.007. [PubMed: 27979325].

5. Kindrat S. The relationship between body image and depression in women diagnosed with relapsing remitting multiple sclerosis. Can J Neurosci Nurs. 2007;29(1):8-13. [PubMed: 18441622].

6. Hasanzadeh P, Fallahi Khoshknab M, Norozi K. Impacts of Journaling on Anxiety and stress in Multiple Sclerosis patients. Complement Med Jfaculty Nurs Midwifery. 2012;2(2):183-93.

7. Mirhashemi M, Najafi . Efficacy of solution-centered therapy on resiliency and sense of coherence among patients with multiple sclerosis. Med Sci J Islamic Azad Univ Tehran Med Branch. 2014;24(3):175-81.

8. Mokhtari A, Allahyari A, Rsvlzadhtbatbayy K. The relationship between religious orientation with stress. Psychology. 2001;1(5):56-67.

9. Noble ML. The Effect of Mainstream Media on Body Image and Stress Reactivity in Latina Females. ; 2012.

10. Murray KM, Byrne DG, Rieger E. Investigating adolescent stress and body image. J Adolesc. 2011;34(2):269-78. doi: 10.1016/j.adolescence.2010.05.004. [PubMed: 20627369].

11. Hughes EK, Gullone E. Emotion regulation moderates relationships between body image concerns and psychological symptomatology. Body Image. 2011;8(3):224-31. doi: 10.1016/j.bodyim.2011.04.001. [PubMed: 21601547].

12. Cakmak A, Cevik E. Cognitive emotion regulation questionnaire: Development of Turkish version of 18-item short form. Afr J Business Manag. 2010;4(10):2097.

13. Turpyn CC, Chaplin TM, Cook EC, Martelli AM. A person-centered approach to adolescent emotion regulation: Associations with psychopathology and parenting. J Exp Child Psychol. 2015;136:1-16. doi: 10.1016/j.jecp.2015.02.009. [PubMed: 25846016].

14. Phillips LH, Saldias A, McCarrey A, Henry JD, Scott C, Summers $\mathrm{F}$, et al. Attentional lapses, emotional regulation and quality of life in multiple sclerosis. Br J Clin Psychol. 2009;48(1):101-6. doi: 10.1348/014466508x379566.

15. Phillips LH, Saldias A, McCarrey A, Henry JD, Scott C, Summers F. Attentional lapses, emotional regulation and quality of life in multiple sclerosis. Br J Clin Psychol. 2009;48(1):101-6.

16. Phillips LH, Henry JD, Nouzova E, Cooper C, Radlak B, Summers F. Difficulties with emotion regulation in multiple sclerosis: Links to executive function, mood, and quality of life. J Clin Exp Neuropsychol. 2014;36(8):831-42. doi: 10.1080/13803395.2014.946891. [PubMed: 25273836].

17. Aghamahammadian Sherbaf H, Modarres Gharavi M, Karashki H. Survey the Effectiveness of Cognitive-Behavioral Group Therapy on Anger reduction in Brain Injured Patients. IJFM. 2014;20(2):37-46.

18. Dostian Y, Bahmani B, Aazami Y, Godini AA. The Relationship between Aggression and Impulsiveness with Susceptibility for Addiction in Male Student. J Rehabil. 2013;14(2):102-9.

19. Sarwa A, Polak K, Sarna D. The influence of the patient's self-image on aetiopathogenesis of the disease. Psychosomatic medicine and psychology of patients with psychosomatic diseases in accordance with threat and challenges of civilization in the modern world. Lodz; 1996.

20. Zanjani Z, Godarzi MA. The study of validity and reliability of Standard Figural Stimuli Scale on Iranian Studentsin Shiraz. J Fundamentals Ment Health. 2008;10(38):149-55.

21. Gleeson K, Frith H. (De)constructing Body Image. J Health Psychol 2016;11(1):79-90. doi: 10.1177/1359105306058851. 
22. Bellino S, Zizza M, Paradiso E, Rivarossa A, Fulcheri M, Bogetto F. Dysmorphic concern symptoms and personality disorders: a clinical investigation in patients seeking cosmetic surgery. Psychiatry Res. 2006;144(1):73-8. doi: 10.1016/j.psychres.2005.06.010. [PubMed: 16914206].

23. Asgari P, Roshanak S. A comparison between the quality of life, life satisfaction, sex role attitude \& self-esteem among students with high and low body image. Thought Behav Clin Psychol. 2010.

24. Noghani F, Monjamed Z, Bahrani N, Ghodrati Jablo V. The comparison of self-esteem between male and female cancer patients. J Hayat. 2006;12(2):33-41.

25. Raghibi M, Minakhany G. Body Management and its Relation with Body Image and Self Concept. Knowledge Res Appl Psychol. 2012;12(46):72-81.

26. Abell N, editor. The Index of Clinical Stress: A brief measure of subjective stress for practice and research. Social Work Research and Abstracts. 1991; Oxford University Press; pp. 12-5.

27. Abell N. The Index of Clinical Stress: A brief measure of subjective stress for practice and research. Soc Work Res Abstracts. 1991;27(2):12-5 doi: 10.1093/swra/27.2.12.

28. Ibanez MI, Ruiperez MA, Moya J, Marques MJ, Ortet G. A Short version of the Self-Regulation Inventory (SRI-S). Pers Individ Differ. 2005;39(6):1055-9. doi:10.1016/j.paid.2005.02.029.

29. Buss AH, Perry M. The aggression questionnaire. J Pers Soc Psychol. 1992;63(3):452-9. [PubMed:1403624].

30. Mohammadi NU. Preliminary psychometric questionnaire Buss Perry. J Human Soc Sci Shiraz. 2006;25(49):135-52.

31. Kartal YA, Kugu N, Semiz M, Kavakci O. The Relationship Between Anger Expression, Body Image and Eating Attitudes in Social Anxiety Disorder. Turk J Psychiatr. 2016;27(1):15-22.

32. Jenssen IH, Johannessen KB. Aggression and body image concerns among anabolic androgenic steroid users, contempla- tors, and controls in Norway. Body Image. 2015;12:6-13. doi: 10.1016/j.bodyim.2014.08.009. [PubMed: 25261635].

33. Kartal Yagiz A, Kugu N, Semiz M, Kavakci O. [The Relationship Between Anger Expression, Body Image and Eating Attitudes in Social Anxiety Disorder]. Turk Psikiyatri Derg. 2016;27(1):15-22. [PubMed: 27369681].

34. Khanjani Z, Bahadori Khosroshahi J. The Prediction of General Health on the Basis of Body Image, Life Stress and Personality Characteristics. Knowledge Res Appl Psychol. 2014;15(58):40-7.

35. Rayegan N, Shaeeiri MR, Asghari MMA. The investigation of cognitivebehavioral therapy influence based on Cash's eight stage model on negative body image of female college students. Clin Psychol Pers. 2006;1(19):11-22.

36. Mohammadi NA, Sajadinezhad MS. The relationship among body image concern, fear of negative evaluation and self-esteem with social anxiety. J Modern Psychol Res. 2007;2(5):55-70.

37. Safir MP, Flaisher-Kellner S, Rosenmann A. When Gender Differences Surpass Cultural Differences in Personal Satisfaction with Body Shape in Israeli College Students. Sex Roles. 2005;52(5-6):369-78. doi: 10.1007/s11199-005-2679-0.

38. Vakili V, Zarifian A, Movahhedianfar F, Bijari M, Ziaee M. Prevalence of aggressive behaviors among the general population of MashhadIran, 2014. J Fundament Ment Health. 2016;18(3).

39. Purshhryary MS. The relationship between shame with dimensions of anger among university students in Tehran. Psychol Stud. 2009;5(3):27-46.

40. Shokri O, Moradi AR, Daneshvar Pour Z, Tarkhan RA. The role of gender differences in copying styles and mental health. Contemp Psychol. 2008;3(1).

41. Martin RC, Dahlen ER. Cognitive emotion regulation in the prediction of depression, anxiety, stress, and anger. Pers Individ Differ. 2005;39(7):1249-60. doi:10.1016/j.paid.2005.06.004. 